Synopsis of Diseases of the Chest. Pare Fraser. (Pp 1000; £69.00.) Philadelphia: Saunders, 1993. 0721636691 .

This beautifully produced book of approximately 1000 pages is an attempt to concentrate much of the essential knowledge from the four volume edition of Diagnosis of Diseases of the Chest by the same authors.

It doesn't really achieve this. The synopsis is really a radiological ride through thoracic medicine. This is clear, for example, when chapter 2 devotes 23 pages to methods of clinical, laboratory, and functional investigation, including lung function tests, yet 90 pages to the subsequent chapter on roentgenologic signs in the diagnosis of chest disease. I do find "roentgenological" grating. "Radiological" sounds much easier and there are not too many departments of roentgenology.

The various chapters, some disease specific, are really descriptive. They concentrate heavily on the radiological appearance of disease and, to a lesser extent, on histological photographs. The book avoids getting involved in treatment. The authors have had to make a decision whether to show gross examples of a problem (I have never seen so many rheumatoid nodules on a chest radiograph before) or to go for more subtle presentations. They go heavily for the former with "chestnut" radiographs often dated from the 1960s and 1970s. Here and there the grossly abnormal radiological appearance lets the book down for some diseases. For example, fibrosing alveolitis is presented in its most abnormal form and yet the use of CT scanning in picking up early development of this disease, and the use of high resolution CT scanning, is hardly dealt with. Here and there the book is clearly somewhat dated.

Nevertheless this is a well produced text, heavily illustrated, giving much information on the radiological appearances of many respiratory conditions. The quality of radiographs throughout the book is good, and the relatively short pieces of text describing the conditions, diagnostic techniques, pathogenesis, etc are to the point.

While this cannot be considered a rival to major textbooks on diseases of the chest (nor does it claim to be so), it is still a thoroughly enjoyable and informative read. It is probably destined for the library rather than the physician's shelf. - SGS

Lung Cancer Differentiation: Implications for Diagnosis and Treatment. (Lung Biology in Health and Disease, Volume 58.) 1st edition. Samuel D Bernal and Paul J Hesketh. (Pp 496; \$175.) New York: Marcel Dekker, 1993. 0824786386.

Much of what is contained in this book was presented at a three day lung cancer conference in 1990. The book is aimed mainly at basic researchers in the molecular approach to lung cell differentiation. The authors also hope it will appeal to clinicians. It is divided into five main sections. The first includes five chapters covering basic studies on differentiation of normal and neoplastic lung epithelial cells and on the links between differentiation and drug resistance. The second section deals with oncogenes and growth factors and the third with biochemical markers of lung cancer differentiation including small cell lung cancer antigens recently clustered by international agreement. The fourth section includes three chapters on the application of differentiation markers in the diagnosis of lung cancer. Sections 5 and 6 include a curious mixture of chapters looking at clinical aspects of lung cancer, protocols for treating non-small cell lung cancer, and the therapy of small cell lung cancer.

The early chapters provide good updates although some are clearly superficial summaries. However, there is much knowledge to be gained from the first two thirds of the book. The presentations are clear with good illustrations and cover the subject well. The book then attempts, for no clear reason, to cover much of the clinical field of lung cancer, including screening, several protocols of therapy for non-small cell lung cancer - with scant critical comment - and finishes with a brief overview of chemotherapy in small cell lung cancer. This is a much less exhaustive volume than most of its predecessors in this series and is rather disappointing. It is a shame that the last third of the book lets down the basic reviews of the initial two thirds. There will be many more rewarding books on the subject than this. - SGS

Indoor Allergens: Assessing and Controlling Adverse Health Effects. A $M$ Pope, R Patterson and $\mathrm{H}$ Burge. (Pp 308; f32.95). Washington: National Academy Press, 1993. 0309048311.

Americans now spend more than $98 \%$ of their life inside buildings or travelling between them, and only 30 minutes of every 24 hours actually out of doors. The trend towards ever more energy efficient and relatively airtight buildings has led to increasing concern about potential adverse health effects of indoor air quality. This prompted the United States Institute of Medicine to sponsor a committee report on the health significance of indoor allergens. The committee not only included allergists and epidemiologists but also experts in engineering and building construction. As a consequence the wide ranging report contains information from $\operatorname{Der} p I$ to cytokines, and from hea exchangers to filtration plant.

With increasing amounts of allergic disease, allergen control strategies have to be the right way forward. However, assessing allergen exposure itself is still an inexact science. Do we look at peak or average exposure? Single site or composite? Airborne or reservoir? The variable individual risk for sensitisation just adds to the complexity.

The report contains eight concise chapters covering the range of allergens, allergic diseases and their immunological basis, risk assessment, engineering control strategies, and the role of education. Each chapter is followed by a set of recommendations and research agenda. The executive summary details in 33 pages what is known (and unknown) about indoor allergens. Some of the report tends to be hard going with some repetition, but overall there is a wealth of information and clearly set targets for the future.

This book will be required reading for everyone interested in the environmental causation of asthma and its control by prevention. If nothing else, the executive summary should be read to see what we ought to be doing over the rest of the decade. - AW
NOTICES

\section{Outcomes into Clinical Practice}

This conference, organised by the BMA, $B M J$, and UK Clearing House on Health Economics, to be held on 7 June 1994 at the International Hotel, Marsh Wall, Docklands, London, will explore the opportunities for outcome assessment in clinical practice: sharing examples of good practice. The meeting is particularly geared to clinical teams in both hospital and general practice. For further details please contact: Pru Walters, BMA House, Tavistock Square, London WC1H 9JP. Telephone: 071383 6518 .

\section{Barcelona 94}

The IInd International Meeting on General Thoracic Surgery, Barcelona 94, will be held in Barcelona on 29 and 30 September 1994. For further information please contact: RCT Asociados, Aulèstia i Pijoan 12, 08012 Barcelona, Spain. Telephone: 34-3-415 69 38. Facsimile: $34-3-4156904$.

\section{Fifth F Ronald Edwards Memorial Lecture}

Dr Hermes Grillo will be delivering the 5th F Ronald Edwards Memorial Lecture on "Tracheal diseases and their management" at The Cardiothoracic Centre, Liverpool on Thursday 9 June 1994 at 5.15 pm. Applications and further information from: $\mathrm{Mr} \mathrm{R} \mathrm{J}$ Donnelly, Medical Director, The Cardiothoracic Centre - Liverpool, NHS Trust, Thomas Drive, Liverpool L14 3PE. Tel: 051 2281616 (Ext 5107).

\section{Respiratory Tract Antioxidants in Health and Disease}

The British Association for Lung Research is organising a meeting on respiratory tract antioxidants in health and disease to be held at St Thomas' Hospital, London, on 19 and 20 September 1994. Deadline for abstracts 16 July 1994. Full programme details and application forms can be obtained from $\mathrm{Dr}$ F J Kelly, Cardiovascular Research, The Rayne Institute, St Thomas' Hospital, London SE1 7EH. Telephone: 0719289292. Fax: 0719280658. 